\title{
Relationship between the lesion location of acute ischemic stroke and early depressive symptoms in Japanese patients
}

\author{
Norifumi Metoki ${ }^{1 \dagger}$, Norio Sugawara ${ }^{2 *}$, Joji Hagii ${ }^{1}$, Shin Saito ${ }^{1}$, Hiroshi Shiroto ${ }^{1}$, Tetsu Tomita ${ }^{2}$, Minoru Yasujima ${ }^{1}$,
} Ken Okumura ${ }^{3}$ and Norio Yasui-Furukori

\begin{abstract}
Background: Approximately one-third of stroke survivors suffer from post-stroke depression (PSD) in the acute or chronic stages. The presence of PSD in the acute stage after stroke is reportedly associated with poor patient prognosis; therefore, early recognition and treatment of PSD may alleviate these consequences. The aim of the current study was to examine the relationship between the lesion location and the presence of early depressive symptoms after acute ischemic stroke in Japanese patients.

Methods: Our study included 421 patients who suffered from acute ischemic stroke. On the day of admission, the lesion location was determined using magnetic resonance imaging (MRI). Stroke severity was measured on the seventh day of hospitalization withat the National Institutes of Health Stroke Scale (NIHSS). On the tenth day of hospitalization, depressive symptoms were measured and functional assessments were performed with the Japan Stroke Scale (Depression Scale) (JSS-D) and functional independence measure (FIM), respectively.

Results: A total of 71 subjects (16.9\%) were diagnosed with depression. According to the multiple logistic regression analysis, the infarcts located at frontal and temporal lobes were found to be a significant independent risk factor of early depressive symptoms in the acute stage of stroke.

Conclusions: Patients suffering from acute ischemic stroke, particularly in the frontal and temporal lobes, should be carefully assessed to detect and treat early depressive symptoms; such treatment may improve patient outcomes.
\end{abstract}

\section{Background}

Post-stroke depression (PSD) is a serious neuropsychiatric complication with a high rate of prevalence after stroke. Approximately one-third of stroke survivors suffer from early or late depressive symptoms after the onset of stroke [1]. Because PSD symptoms are related to increased functional disability [2] and poorer rehabilitation outcomes [3], the factors associated with PSD are of great clinical importance.

Compared with patients who develop depressive symptoms later, patients who develop PSD during the

\footnotetext{
*Correspondence: nsuga3@yahoo.co.jp

${ }^{\dagger}$ Norifumi Metoki and Norio Sugawara contributed equally to this work

${ }^{2}$ Department of Neuropsychiatry, Hirosaki University School of Medicine,

5 Zaifu-cho, Hirosaki 036-8562, Aomori, Japan

Full list of author information is available at the end of the article
}

acute stage of stroke demonstrate more somatic signs of depression rather than endogenous signs of depression [4], and they more frequently show early signs of melancholy, vegetative state, and psychological disturbance with poor social skills [5]. In addition, several longitudinal studies have shown that the incidence of PSD is higher in the first month post-stroke [6-8] compared with later in the first year after stroke. Although it is difficult to prevent stroke, the early screening and treatment of PSD in the acute stage may be the key to alleviating its long-term consequences.

In addition to psychological reactions due to disability, loss of independence, and impaired quality of life (QOL) [9], pathophysiological factors, such as changes in neurotransmitters [10] and the specific site of infarcts [11], have also been hypothesized to be related to the 
development of PSD. Indeed, the relationship between the stroke lesion locations and PSD has been the topic of much research [12]. Although many studies of PSD, including meta-analyses, have been reported, the association between the lesion location and the occurrence of PSD remains unclear [13-15], likely because of the variables, such as time post-stroke, and the type of instruments used to assess PSD.

The objectives of this investigation were (1) to evaluate the prevalence of early depressive symptoms among patients with acute ischemic stroke and (2) to examine the relationship between the lesion location and presence of early depressive symptoms. To our knowledge, this study is the largest to date in a Japanese population.

\section{Methods}

\section{Participants}

We reviewed the charts of 532 patients who were admitted for acute stroke between April 2012 and March 2013 at Hirosaki Stroke and Rehabilitation Center. The stroke diagnosis was based on both the presence of acute neurological symptoms and a compatible lesion on magnetic resonance imaging (MRI) on the first day of hospitalization. We excluded patients with (1) serious comprehension difficulties (e.g., severe aphasia), (2) hemorrhage, and (3) a history of psychiatric disease (e.g., depression, dementia, etc.). Psychiatric histories were obtained from medical records based on interviewing patients and family. After a detailed evaluation with inclusion and exclusion criteria, 421 patients who suffered from acute ischemic stroke participated in this study. The following information was collected for each patient: demographics (i.e., age, gender, education level, and living alone) and stroke severity, as measured with the National Institutes of Health Stroke Scale (NIHSS) on the seventh day of hospitalization [16]. Assessment of NIHSS scale was performed by trained stroke nurses, and the testing was confirmed by neurologists.

The data collection for this study was approved by the Ethics Committee of the Hirosaki University School of Medicine and Hirosaki Stroke and Rehabilitation Center. Informed consent was obtained from all patients before the study.

\section{Assessment of early depressive symptoms and functional independence}

The Japan Stroke Scale (Depression Scale) (JSS-D), which was developed by the Japan Stroke Society, was administered to all participants to measure their depressive status [17]. The JSS-D is a 7-item (i.e., mood, guilt feelings, interest, apathy, anxiety, sleeplessness, and expression) objective measurement, in which three choices are given for each item. The total score, which indicates the degree of depression, was calculated based on the proper weight of each choice. Based on ROC curve analysis of JSS-D, probable PSD was defined as a score of 2.4 or higher. The sensitivity and specificity of this cut-off score were 0.950 and 0.988 , respectively [17]. In this study, JSS-D data were collected on the tenth day of hospitalization to assess depressive symptoms in acute post-stroke phase ( $\leq 1$ month). Assessment of JSS-D was performed by trained stroke nurses, and the testing was confirmed by psychiatrists.

Functional independence was assessed with the 18-item functional independence measure (FIM), which consists of six domains: self-care, sphincter control, mobility, locomotion, communication, and social cognition. The FIM scores a patient's dependence level from 18 (total assistance in all areas) to 126 (complete independence in all areas) [18] and were administered on the tenth day of hospitalization. Assessment of FIM was performed by trained stroke nurses, and the testing was confirmed by neurologists.

\section{Brain imaging}

We performed MRI (Signa EXCITE HD 1.5T; GE Medical Systems, Waukesha, USA), including transversal diffusion weighted imaging (DWI), T2-weighted imaging, and fluid-attenuated inversion recovery (FLAIR). In terms of the lesion classifications, information about the infarct site included the affected brain lobes (i.e., frontal, temporal, parietal, and occipital lobe) and the specific anatomical structure/location (i.e., thalamus, caudate, putamen, anterior and posterior limb of internal capsule, corona radiata, centrum semiovale, hippocampus, and amygdala). Stroke specialist physicians certified by Japan stroke society analyzed the images.

\section{Statistical analysis}

Descriptive analyses of the demographic and clinical variables were performed. To perform between-group comparisons of the main demographic and clinical characteristics of the patients, an unpaired Student's $t$ test was performed to analyze continuous variables, and a Chi-squared test or Fisher's exact test was performed to analyze categorical variables. Data are presented as the mean $\pm \mathrm{SD}$. All variables with $p<0.10$ in the univariate analysis were subsequently analyzed by multivariate logistic regression. For confounding factors, including age, gender, education level, living alone, and NIHSS and FIM scores, multivariate logistic regression analysis was applied to assess the relationship between the lesion location and probable PSD, with a significance level of $p<0.05$. Data were analyzed using the PASW Statistics PC software for Windows, version 18.0.0 (SPSS Inc., Chicago, IL, USA). 


\section{Results}

\section{Patient characteristics}

The mean JSS-D score was $1.53 \pm 1.62$ for males and $1.77 \pm 2.24$ for females $(p>0.05)$. The prevalence of probable PSD (based on a JSS-D cut-off of 2.4) (17) was $16.3 \%$ in males $(n=43)$ and $17.8 \%$ in females $(n=28)$ $(p>0.05)$. Table 1 shows the characteristics of the subjects with and without depressive symptoms.

\section{Logistic regression analysis}

The lesion locations in patients with and without depressive symptoms are shown in Table 2 . The infarct more frequently affected the following locations in the probable PSD group compared with the non-PSD group: the frontal lobe $(p<0.001)$, temporal lobe $(p<0.001)$, parietal lobe $(p=0.011)$, and putamen $(p=0.011)$, when both sides were considered. To examine the potential independent radiological factors for the development of probable PSD, we included radiological findings with $p<0.10$ from the univariate analysis in a multiple logistic regression model, which used adjusted factors including age, gender, and post-stroke NIHSS and FIM scores. This analysis suggested that independent radiological risk factors for probable PSD might include infarcts located at the frontal and temporal lobes (Table 3).

\section{Discussion}

In this study, the prevalence of PSD (based on the JSS-D score) was $16.9 \%$ in the early stroke period. The prevalence of PSD in our study was within the range of previous results, ranging from 6 to $37 \%$ [19-22]. This study of lesion locations demonstrated that frontal and temporal lobe area infarctions are significantly and independently associated with depressive symptoms at the tenth day of hospitalization.

In the 1980s, Robinson and colleagues [23] first showed that depression scores based on both Zung and Hamilton rating scales were significantly higher in patients with left frontal lesions than in patients with lesions in any other location, indicating that there may be an association between specific lesion locations and mood disorder in patients who suffered from acute stroke. Subsequently, several studies [24-27] have also shown that PSD was associated with lesions in the frontal lobes, basal ganglia, and temporal lobes. Recent studies have further demonstrated a relationship between the limbic-corticalstriatal-pallidal-thalamic (LCSPT) circuit and the pathophysiology of major depressive disorder [28, 29]. Terroni and colleagues have reported that among patients with ischemic stroke, larger lesions in the left cortical regions of the LCSPT circuit are associated with a higher incidence of major depressive episode [30]. Together, these findings support our results and indicate that ischemic lesions in certain areas can increase the risk of PSD. However, our results concerning hemispheric lateralization should be cautiously interpreted, because a recent meta-analysis observed that hemispheric laterality of ischemic lesions was not associated with the onset of PSD in an acute post-stroke subgroup [11].

To date, the depletion of biogenic amine neurotransmitters or alterations in their post-synaptic receptor sensitivities have been thought to play important roles in the development of PSD [10], and several studies have investigated medication for PSD [31, 32]. However, it should be noted that many PSD patients may not receive effective treatment for their mood disorders. To improve the long-term outcomes of stroke, it is important to provide early screening and treatment for PSD in the acute stage.

One strength of this study was the use of MRI to assess the infarct site. Many previous studies of PSD have used computed tomography (CT), whereas few studies in this field have used MRI. For detection of acute ischemic stroke, MRI provides greater image resolution, which can identify the site and extent of the infarct with more sensitivity than CT $[33,34]$.

The current findings must be cautiously interpreted for the following reasons. First, this study used only one measure of depressive symptoms, the JSS-D, and patients

Table 1 Characteristics according to subjects with and without depressive symptoms

\begin{tabular}{llll}
\hline & Subjects with probable PSD & Subjects without probable PSD & $\boldsymbol{p}$ value \\
\hline$n$ & 71 & 350 & 0.052 \\
Age & $74.4 \pm 11.1$ & $71.6 \pm 11.2$ & 0.682 \\
Gender & Male 43, & Male 221, \\
& Female 28 & Female 129 & $0.8 \pm 2.5$ \\
Amount of education (year) & $9.9 \pm 2.8$ & 54 & 0.936 \\
Living alone & 10 & $2.7 \pm 3.4$ & 0.767 \\
NIHSS total score & $6.3 \pm 5.2$ & $102.2 \pm 28.4$ & $<0.001$ \\
FIM total score & $72.7 \pm 34.2$ & $<.001$ \\
\hline
\end{tabular}

PSD post-stroke depression, NIHSS National institutes of health stroke scale, FIM functional independence measure 
Table 2 Lesion location in patients with and without depressive symptoms

\begin{tabular}{|c|c|c|c|c|c|}
\hline & \multicolumn{2}{|c|}{$\begin{array}{l}\text { Subjects with } \\
\text { probable PSD } \\
(n=71)\end{array}$} & \multicolumn{2}{|c|}{$\begin{array}{l}\text { Subjects with- } \\
\text { out probable } \\
\text { PSD }(n=350)\end{array}$} & \multirow[t]{2}{*}{$p$ value } \\
\hline & $n$ & $\%$ & $n$ & $\%$ & \\
\hline \multicolumn{6}{|l|}{ Frontal lobe } \\
\hline Any side & 18 & 25.4 & 30 & 8.6 & $<0.001$ \\
\hline Left side & 7 & 9.9 & 14 & 4.0 & 0.065 \\
\hline Right side & 11 & 15.5 & 16 & 4.6 & $<0.01$ \\
\hline \multicolumn{6}{|c|}{ Temporal lobe } \\
\hline Any side & 18 & 25.4 & 28 & 8.0 & $<0.001$ \\
\hline Left side & 7 & 9.9 & 12 & 3.4 & 0.027 \\
\hline Right side & 11 & 15.5 & 16 & 4.6 & 0.002 \\
\hline \multicolumn{6}{|l|}{ Parietal lobe } \\
\hline Any side & 18 & 25.4 & 47 & 13.4 & 0.011 \\
\hline Left side & 9 & 12.7 & 21 & 6.0 & 0.046 \\
\hline Right side & 10 & 14.1 & 33 & 9.4 & 0.238 \\
\hline \multicolumn{6}{|c|}{ Occipital lobe } \\
\hline Any side & 10 & 14.1 & 37 & 10.6 & 0.391 \\
\hline Left side & 3 & 4.2 & 16 & 4.6 & 1.000 \\
\hline Right side & 7 & 9.9 & 22 & 6.3 & 0.302 \\
\hline \multicolumn{6}{|l|}{ Thalamus } \\
\hline Any side & 6 & 8.5 & 42 & 12.0 & 0.391 \\
\hline Left side & 2 & 2.8 & 20 & 5.7 & 0.556 \\
\hline Right side & 4 & 5.6 & 24 & 6.9 & 1.000 \\
\hline \multicolumn{6}{|l|}{ Caudate } \\
\hline Any side & 6 & 8.5 & 13 & 3.7 & 0.109 \\
\hline Left side & 3 & 4.2 & 9 & 2.6 & 0.434 \\
\hline Right side & 3 & 4.2 & 4 & 1.1 & 0.097 \\
\hline \multicolumn{6}{|l|}{ Putamen } \\
\hline Any side & 18 & 25.4 & 47 & 13.4 & 0.011 \\
\hline Left side & 7 & 9.9 & 16 & 4.6 & 0.086 \\
\hline Right side & 11 & 15.5 & 31 & 8.9 & 0.089 \\
\hline \multicolumn{6}{|c|}{ Anterior limb of internal capsule } \\
\hline Any side & 6 & 8.5 & 13 & 3.7 & 0.109 \\
\hline Left side & 3 & 4.2 & 7 & 2.0 & 0.383 \\
\hline Right side & 3 & 4.2 & 6 & 1.7 & 0.181 \\
\hline \multicolumn{6}{|c|}{ Posterior limb of internal capsule } \\
\hline Any side & 6 & 8.5 & 33 & 9.4 & 0.796 \\
\hline Left side & 2 & 2.8 & 16 & 4.6 & 0.505 \\
\hline Right side & 4 & 5.6 & 17 & 4.9 & 0.766 \\
\hline \multicolumn{6}{|c|}{ Corona radiata } \\
\hline Any side & 23 & 32.4 & 111 & 31.7 & 0.911 \\
\hline Left side & 9 & 12.7 & 61 & 17.4 & 0.327 \\
\hline Right side & 14 & 19.7 & 50 & 14.3 & 0.245 \\
\hline \multicolumn{6}{|c|}{ Centrum semiovale } \\
\hline Any side & 12 & 16.9 & 47 & 13.4 & 0.442 \\
\hline Left side & 5 & 7.0 & 20 & 5.7 & 0.591 \\
\hline Right side & 7 & 9.9 & 28 & 8.0 & 0.605 \\
\hline \multicolumn{6}{|c|}{ Hippocampus } \\
\hline Any side & 3 & 4.2 & 15 & 4.3 & 0.982 \\
\hline
\end{tabular}

Table 2 continued

\begin{tabular}{|c|c|c|c|c|c|}
\hline & \multicolumn{2}{|c|}{$\begin{array}{l}\text { Subjects with } \\
\text { probable PSD } \\
(n=71)\end{array}$} & \multicolumn{2}{|c|}{$\begin{array}{l}\text { Subjects with- } \\
\text { out probable } \\
\text { PSD }(n=350)\end{array}$} & \multirow[t]{2}{*}{$p$ value } \\
\hline & $n$ & $\%$ & $n$ & $\%$ & \\
\hline Left side & 2 & 2.8 & 7 & 2.0 & 0.652 \\
\hline Right side & 2 & 2.8 & 8 & 2.3 & 0.679 \\
\hline \multicolumn{6}{|l|}{ Amygdala } \\
\hline Any side & 0 & 0.0 & 5 & 1.4 & 0.595 \\
\hline Left side & 0 & 0.0 & 1 & 0.3 & 1.000 \\
\hline Right side & 0 & 0.0 & 4 & 1.1 & 1.000 \\
\hline
\end{tabular}

PSD post-stroke depression

Table 3 Lesion locations associated with having depressive symptoms estimated by logistic regression analysis

\begin{tabular}{|c|c|c|c|}
\hline Lesions & $\begin{array}{l}\text { Adjusted } \\
\text { odds ratio }\end{array}$ & $\begin{array}{l}95 \% \text { Confidence } \\
\text { interval }\end{array}$ & $p$ value \\
\hline \multicolumn{4}{|l|}{ Frontal lobe } \\
\hline Any side & 2.534 & $1.188-5.403$ & 0.016 \\
\hline Left side & 1.849 & $0.607-5.636$ & 0.279 \\
\hline Right side & 2.709 & $1.057-6.946$ & 0.038 \\
\hline \multicolumn{4}{|c|}{ Temporal lobe } \\
\hline Any side & 3.082 & $1.454-6.535$ & 0.003 \\
\hline Left side & 2.363 & $0.794-7.038$ & 0.122 \\
\hline Right side & 3.093 & $1.212-7.895$ & 0.018 \\
\hline \multicolumn{4}{|l|}{ Parietal lobe } \\
\hline Any side & 1.500 & $0.739-3.045$ & 0.262 \\
\hline Left side & 2.201 & $0.871-5.565$ & 0.095 \\
\hline \multicolumn{4}{|l|}{ Caudate } \\
\hline Right side & 6.936 & $1.328-36.237$ & 0.022 \\
\hline \multicolumn{4}{|l|}{ Putamen } \\
\hline Any side & 1.933 & $0.956-3.908$ & 0.067 \\
\hline Left side & 1.795 & $0.603-5.339$ & 0.293 \\
\hline Right side & 1.803 & $0.782-4.156$ & 0.166 \\
\hline
\end{tabular}

were not diagnosed with clinical depression using the Diagnostic and Statistical Manual of Mental Disorders, Fourth Edition. Although JSS-D screening has been well validated and is widely used to assess depressive symptoms, this tool is not a formal diagnostic tool for depression. In addition, the PSD assessment was conducted on the tenth day of hospitalization. Although half of the median reported prehospital delays ranging from 3 to $4 \mathrm{~h}$ [35], we cannot completely rule out delays from onset to admission. Second, lesion size was not assessed in this study. Although some studies have not shown an association between lesion size and PSD [24, 36], other studies have reported that lesion size could affect the 
development of PSD [25, 37]. Third, some important factors, such as medical complications and medication, were not assessed by our study. Finally, we excluded subjects with severe comprehension difficulties because they could not complete the evaluation, which could limit the generalization of our findings.

\section{Conclusions}

Our study found that the prevalence of PSD based on JSS-D was $17 \%$, which is in agreement with comparable studies. Patients who have suffered from ischemic stroke, particularly in the frontal and temporal lobes, should be carefully evaluated for early detection and treatment of depressive symptoms.

\section{Authors' contributions}

NM and NS conceived and designed the study, conducted the statistical analysis, interpreted the data, and wrote the initial draft of the manuscript. NYF had full access to all of the data in the study and takes responsibility for the integrity of the data and the accuracy of the data analysis. MY contributed to study design and assisted in drafting the manuscript. TT and KO completed initial survey construction and recruitment of participants. JH, SS, and HS participated in the data collection and the interpretation of the results. All authors read and approved the final manuscript.

\section{Author details}

${ }^{1}$ Hirosaki Stroke and Rehabilitation Center, Hirosaki, Japan. ${ }^{2}$ Department of Neuropsychiatry, Hirosaki University School of Medicine, 5 Zaifu-cho, Hirosaki 036-8562, Aomori, Japan. ${ }^{3}$ Department of Cardiology, Hirosaki University School of Medicine, Hirosaki, Japan.

\section{Acknowledgements}

We are grateful to all volunteers who participated in this study. The authors would also like to express their gratitude to Ms. Sachie Narita, Ms. Ruriko Ono, Ms. Ayako Osanai, Ms. Ayako Kudo, and Ms. Kiho Koie for their help with this study.

\section{Competing interests}

The authors declare that they have no competing interests.

Received: 7 January 2016 Accepted: 23 March 2016

Published online: 01 April 2016

\section{References}

1. Hackett ML, Yapa C, Parag V, Anderson CS. Frequency of depression after stroke: a systematic review of observational studies. Stroke. 2005;36:1330-40.

2. Cully JA, Gfeller JD, Heise RA, Ross MJ, Teal CR, Kunik ME. Geriatric depression, medical diagnosis, and functional recovery during acute rehabilitation. Arch Phys Med Rehabil. 2005;86:2256-60.

3. Gillen R, Tennen H, McKee TE, Gernert-Dott P, Affleck G. Depressive symptoms and history of depression predict rehabilitation efficiency in stroke patients. Arch Phys Med Rehabil. 2001;82:1645-9.

4. Beblo T, Driessen M. No melancholia in poststroke depression? A phenomenologic comparison of primary and poststroke depression. J Geriatr Psychiatry Neurol. 2002;15:44-9.

5. Tateno A, Kimura M, Robinson RG. Phenomenological characteristics of poststroke depression: early—versus late-onset. Am J Geriatr Psychiatry. 2002;10:575-82.

6. Leentjens AF, Aben I, Lodder J, Verhey FR. General and disease-specific risk factors for depression after ischemic stroke: a two-step Cox regression analysis. Int Psychogeriatr. 2006;18:739-48.

7. Morrison V, Pollard B, Johnston M, MacWalter R. Anxiety and depression 3 years following stroke: demographic, clinical, and psychological predictors. J Psychosom Res. 2005;59:209.
8. Niedermaier N, Bohrer E, Schulte K, Schlattmann P, Heuser I. Prevention and treatment of poststroke depression with mirtazapine in patients with acute stroke. J Clin Psychiatry. 2004;65:1619-23.

9. Hadidi N, Treat-Jacobson DJ, Lindquist R. Poststroke depression and functional outcome: a critical review of literature. Heart Lung. 2009;38:151-62.

10. Loubinoux I, Kronenberg G, Endres M, Schumann-Bard P, Freret T, Filipkowski RK, Kaczmarek L, Popa-Wagner A. Post-stroke depression: mechanisms, translation and therapy. J Cell Mol Med. 2012;16:1961-9.

11. Wei N, Yong W, Li X, Zhou Y, Deng M, Zhu H, Jin H. Post-stroke depression and lesion location: a systematic review. J Neurol. 2014 (in press).

12. Hama S, Yamashita H, Yamawaki S, Kurosi K. Post-stroke depression and apathy: interactions between functional recover, lesion detection, and emotional response. Psychogeriatrics. 2011;11:68-76.

13. Robinson RG, Kubos KL, Starr LB, Rao K, Price TR. Mood changes in stroke patients: relationship to lesion location. Compr Psychiatry. 1983;24:555-66.

14. Carson AJ, MacHale S, Allen K, Lawrie SM, Dennis M, House A, Sharpe M. Depression after stroke and lesion location: a systematic review. Lancet. 2000;356:122-6.

15. Bhogal SK, Teasell R, Foley N, Speechley M. Lesion location and poststroke depression: systematic review of the methodological limitations in the literature. Stroke. 2004;35:794-802.

16. Brott T, Adams HP Jr, Olinger CP, Marler JR, Barsan WG, Biller J, Spilker J, Holleran R, Eberle R, Hertzberg V, Rorick M, Moomaw CJ, Walker M. Measurements of acute cerebral infarction: a clinical examination scale. Stroke. 1989;20:864-70.

17. Kaji Y, Hirata K. Usefulness of the Japan Stroke Scale-Depression Scale-(JSS-D) for the diagnosis of post-stroke depression. Intern Med. 2008;47:225-9.

18. Keith RA, Granger CV, Hamilton BB, Sherwin FS. The functional independence measure: a new tool for rehabilitation. Adv Clin Rehabil. 1987;1:6-18.

19. Whyte EM, Mulsant BH. Post-stroke depression: epidemiology, pathophysiology, and biological treatment. Biol Psychiatry. 2002;52:253-64.

20. Gonzalez-Torrecillas J, Mendlewicz J, Lobo A. Effects of early treatment of poststroke depression on neuropsychological rehabilitation. Int Psychogeriatr. 1995;7:547-60.

21. Shima S, Kitagawa Y, Kitamura T, Fujinawa A, Watanabe Y. Poststroke depression. Gen Hosp Psychiatry. 1994;16:286-9.

22. Palomäki H, Kaste M, Berg A, Lönnqvist R, Lönnqvist J, Lehtihalmes $M$, Hares J. Prevention of poststroke depression: 1 year randomised placebo controlled double blind trial of mianserin with 6 month follow up after therapy. J Neurol Neurosurg Psychiatry. 1999;66:490-4.

23. Robinson RG, Starr LB, Kubos KL, Price TR. A two-year longitudinal study of post-stroke mood disorders: findings during the initial evaluation. Stroke. 1983;14:736-41.

24. Astrom M, Adolfsson R, Asplund K. Major depression in stroke patients: a 3-year longitudinal study. Stroke. 1993;24:976-82.

25. Shimoda K, Robinson RG. The relationship between poststroke depression and lesion location in long-term follow-up. Biol Psychiatry. 1999;45:187-92.

26. Nishiyama Y, Komaba Y, Ueda M, Nagayama H, Amemiya S, Katayama Y. Early depressive symptoms after ischemic stroke are associated with a left lenticulocapsular area lesion. J Stroke Cerebrovasc Dis. 2010;19:184-9.

27. Yang S, Hua P, Shang X, Hu R, Mo X, Pan X. Predictors of early post ischemic stroke apathy and depression: a cross-sectional study. BMC Psychiatry. 2013;13:164.

28. Drevets WC, Price JL, Furey ML. Brain structural and functional abnormalities in mood disorders: implications for neurocircuitry models of depression. Brain Struct Funct. 2008;213:93-118.

29. Hasler G, Fromm S, Carlson PJ, Luckenbaugh DA, Waldeck T, Geraci M, Roiser JP, Neumeister A, Meyers N, Charney DS, Drevets WC. Neural response to catecholamine depletion in unmedicated subjects with major depressive disorder in remission and healthy subjects. Arch Gen Psychiatry. 2008;65:521-31.

30. Terroni L, Amaro E, losifescu DV, Tinone G, Sato JR, Leite CC, Sobreiro MF, Lucia MC, Scaff M, Fráguas R. Stroke lesion in cortical neural circuits and post-stroke incidence of major depressive episode: a 4-month prospective study. World J Biol Psychiatry. 2011;12:539-48.

31. Metoki H, Kanazawa T, Nihei C, Komatsu O, Ishiyama T, Sasaki N, Sawai M, Ito F, Jin Y, Nakamichi S, Murakami S, Shoji B, Yoshioka H, Koishi Y, Saito H, Kaneko H, Yoshida J, Onodera K. Study of availability from little 
administration of amantadine hydrochloride for cerebral infarction patient with volition, initiative lowering. Diagn Treat. 1993;30:2265-79 (in Japanese)

32. Narushima K, Robinson RG. The effect of early versus late antidepressant treatment on physical impairment associated with poststroke depression: is there a time-related therapeutic window? J Nerv Ment Dis. 2003;191:645-52.

33. Brazzelli M, Sandercock PA, Chappell FM, Celani MG, Righetti E, Arestis $\mathrm{N}$, Wardlaw JM, Deeks JJ. Magnetic resonance imaging versus computed tomography for detection of acute vascular lesions in patients presenting with stroke symptoms. Cochrane Database Syst Rev. 2009;4:CD007424
34. Hall C, Lang E. Evidence-based emergency medicine. Is MRI more accurate than CT in patients with suspected acute stroke? Ann Emerg Med. 2011;58:99-100

35. Evenson KR, Foraker RE, Morris DL, Rosamond WD. Comprehensive review of prehospital and in-hospital delay times in acute stroke care. Int J Stroke. 2009;4:187-99.

36. Robinson RG, Starr LB, Lipsey JR, Rao K, Price TR. A two-year longitudinal study of post-stroke mood disorders: dynamic changes in associated variables over the first 6 months of follow-up. Stroke. 1984;15:510-7.

37. Nys GM, van Zandvoort MJ, van der Worp HB, de Haan EH, de Kort PL, Kappelle LJ. Early depressive symptoms after stroke: neuropsychological correlates and lesion characteristics. J Neurol Sci. 2005;228:27-33.

\section{Submit your next manuscript to BioMed Central and we will help you at every step:}

- We accept pre-submission inquiries

- Our selector tool helps you to find the most relevant journal

- We provide round the clock customer support

- Convenient online submission

- Thorough peer review

- Inclusion in PubMed and all major indexing services

- Maximum visibility for your research

Submit your manuscript at www.biomedcentral.com/submit
() Biomed Central 